\title{
Patient empowerment: the LIFE approach
}

\author{
MM Funnell, * MA Weiss
}

'You can teach me, but you can't make me!', exclaimed the lady as she stood and shook her finger at the physician sitting across the table from her at a recent community diabetes forum. The woman was in her 50s, had been diagnosed with type 2 diabetes several years before, and did not appear familiar with any of the current literature on diabetes educational theories. Yet, by her statement, she understood fully. Somehow, she had deciphered for herself that only she not her healthcare professionals, nor her family members - had the power to manage her diabetes. She understood that the many daily decisions she faced could be made and implemented only by her. She understood that diabetes is a selfmanaged disease, and that she was the 'self'. Her statement described empowerment perfectly.

Authors
MM Funnell,' ${ }^{1}$ MS, RN, CDE, Research
Investigator; Clinical Nurse Specialist
MA Weiss, ${ }^{2}$ Managing Director of Patient-
Centred Solutions; Chair of ADA 2002-3
'The Department of Medical Education
and the Michigan Diabetes Research and
Training Center, University of Michigan
Medical School, Ann Arbor, Michigan
2Patient-Centred Solutions, Pittsburgh,
PA, USA
*Correspondence to:
MM Funnell, 300 N. Ingalls, 3D06,
Box 5489, University of Michigan,
Ann Arbor, Michigan 48109-5489, USA
e-mail: mfunnell@umich.edu
Received: 29 October 2007
Accepted in revised form:
07 December 2007

\section{Summary}

In spite of the great strides that have been made in the treatment of diabetes, many patients do not achieve optimal outcomes. In an effort to address the gap between the promise and the reality of diabetes care, empowerment has been recognised as an effective patient-centred approach to diabetes care and education. A great deal of effort has been spent training healthcare professionals and developing patient education strategies within this framework. However, less effort has been spent helping patients to learn the lessons and acquire the skills needed to collaborate in the design of a workable diabetes care plan. This article outlines four fundamental lessons that need to be addressed as part of patient education and provides a simple approach called the LIFE plan to help patients truly take charge of their diabetes.

Eur Diabetes Nursing 2008; 5(2): 75-78.

\section{Key Words}

Patient-centred; LIFE plan; diabetes self-management; patient education; self-management support

\section{Patient empowerment}

Despite the great strides that have been made in the treatment of diabetes in recent years, many patients do not achieve optimal outcomes. As a result, these patients experience devastating complications that result in a decreased length and quality of life. Traditionally, the success of healthcare professionals and patients was judged by the achievement of recommended outcomes through adherence to a prescribed regimen. In spite of many wellintentioned efforts to develop and study methods to promote adherence, the traditional approach did not match the reality of diabetes care. ${ }^{1}$ The serious and chronic nature of diabetes, the complexity of its management, and the multiple daily self-care decisions that diabetes requires led to the growing recognition that a different approach was needed. Patient empowerment ${ }^{2-4}$ was proposed as an approach which recognised that patients are in control of and responsible for the daily selfmanagement of diabetes. In order to be successfully implemented, a self-management plan had to fit patients' goals, priorities, and lifestyle needs and choices, as well as the pathology of their diabetes.

Empowerment is a patientcentred, collaborative approach designed to match the fundamental realities of diabetes care..$^{2,5,6}$ Patient empowerment is defined as helping patients discover and develop the inherent capacity to be responsible for their own health and life. ${ }^{2}$ Since initially proposed in diabetes, there has been a growing recognition that although healthcare professionals are experts on diabetes care, patients are the experts on their own lives. ${ }^{5,7-9}$ This approach acknowledges that knowing about an illness is not the same as knowing about the effects of that illness on a person's life. By default, patients are the primary decision-makers in control of the daily self-management of their diabetes. 
Embracing this philosophy requires that healthcare professionals practice in ways that are consistent with this approach. ${ }^{2,4,10}$ Since it was first proposed, ${ }^{2}$ multiple programmes and strategies have been developed to teach healthcare professionals how to practise within this framework. These include training healthcare professionals in empowermentbased strategies ${ }^{11,12}$ such as activelistening, problem-solving and goal-setting. In addition, programmes designed to teach the skills of empowerment, or patient self-management education that incorporates these skills, have been shown to be effective. ${ }^{13-21}$ Empowerment has even been addressed in the field of healthcare system design. For example, the Chronic Care Model $^{22}$ has as its foundation an informed and empowered patient working with a proactive healthcare team.

Less attention, however, has been paid to translating empowerment to patients by providing simple, easy-to-use strategies that they can implement in their daily lives. Before one can consider these strategies, it is necessary that the empowerment concept itself be added to the core curriculum for diabetes patient education. It is imperative that diabetes patients be helped to understand from the outset that they are the only ones who can effectively manage their condition. This is true whether it means taking prescribed medications, using a meal plan or participating in physical activity. The fact that diabetes is a self-managed illness needs to be the very first lesson in all diabetes education.

Whatever the care plan entails, it seldom works when created wholly by prescription. There is ample empirical evidence $e^{1,13,23}$ that the most successful diabetes self-management plans are those that have been developed by the patients themselves, working in close collaboration with their healthcare providers. Medicines, meal plans and physical activity programmes are most likely to fit the patient's particular life circumstances and are more likely to be implemented when patients are actively involved.

Nurses need to provide patients with the available resources for developing such a plan. An important finding of the Diabetes Attitudes, Wishes and Needs (DAWN) study ${ }^{24}$ was that less than $20 \%$ of people with type 1 diabetes and less than $17 \%$ of people with type 2 diabetes indicated that they actually do everything their healthcare providers have recommended to manage their condition. These findings were more recently confirmed in the Study to Help Improve Early evaluation and management of risk factors Leading to Diabetes (SHIELD). ${ }^{25}$ In spite of knowledge and attitudes conducive to good health, the majority of SHIELD participants did not translate these traits into healthy behaviours. Along with substantiating the ineffectiveness of physicianmandated approaches, these studies validated the anecdotal experiences of many nurses. Patients report that they know what they want to do, but just do not know how to do those things. The 'how' needs to be the second lesson in diabetes education.

\section{Think LIFE}

One approach that can be used by nurses or primary care providers to help patients create a workable plan is the LIFE approach. ${ }^{26,27}$ Although not yet empirically tested, this approach was developed through years of experience in empowerment-based education and care. LIFE provides a framework that addresses the fundamental skills of empowerment in an easily understood, patient-centred manner.

LIFE consists of four distinct but very fluid steps:

- Step 1: Learn about diabetes, the healthcare team and personal life circumstances

- Step 2: Identify three guiding principles: role, flexibility and targets

- Step 3: Formulate a personal self-management plan

- Step 4: Experiment with and evaluate the plan.

\section{Learn}

Diabetes education occurs at two levels. While it is important for patients to learn about diabetes and how to manage it, it is equally important for patients to understand how diabetes affects them personally. The concept of 'real diabetes' does not just encompass how an individual's body reacts to drugs and other therapies. As the DAWN study illuminated, it is equally important for patients to understand their prevailing feelings, wants, needs and capabilities. This requires honest reflection on the part of the patient and a high degree of sensitivity, empathy and understanding on the part of healthcare professionals.

Healthcare professionals are experts about diabetes and will have many valuable recommendations. However, it is the people with diabetes who are truly expert about their own diabetes - how it affects them physically, emotionally and practically. Nurses can facilitate this process by asking patients about their concerns, feelings, priorities, other life stresses and goals. Using active listening strategies, nurses can then help patients to devise a plan that fits their lives, rather than expecting patients to adapt their lives to accommodate diabetes. 
It is also important to help patients identify their sources of emotional and practical support. For most people, the primary support team will consist of family members. It is not uncommon, however, for some to seek support from friends, healthcare professionals, clergy and other people with diabetes. The important thing is for them to have someone with whom to share worries and concerns. Both the support and healthcare teams need to know what the patient needs and expects from them. This should reduce potential frustration and misunderstandings. In turn, nurses and other members of the support team need to help patients understand what they can realistically offer.

\section{Identify the guiding principles}

Role of the patient in the creation of the self-management plan. In this step, nurses help patients to identify the ground rules for how they will manage their diabetes. First, patients must decide how actively involved they want to be in the creation of their personal selfmanagement plan. One option to offer patients is to allow their healthcare providers to design the entire plan. This option may be helpful when diabetes is first diagnosed or until there is a better sense of the patient's personal needs, likes and other circumstances that need to be incorporated into the plan. Alternatively, the patient may choose to become an integral member of the plan design team. Neither of these options is right or wrong. The important thing is to help patients develop a plan that can be used effectively. As the patient's comfort level with diabetes management increases, the patient may assume a more active role. It may also be that the first option works for some aspects of the plan while the second option works better for others. For example, patients may choose to accept healthcare provider recommendations about medications, but design their own activity or meal plan.

Flexibility. Nurses need to help patients consider how much flexibility they want and need in their lives. Some people find it easier to follow a strict meal plan and timetable. Others want the ability to change their daily routines to suit their own schedules. Once again, patients have a choice to make and need to appreciate the costs and benefits of the various options. For instance, in order to have more flexibility, it will be necessary to make more daily decisions and monitor blood glucose levels more often. More flexibility may also require more insulin injections. On the other hand, creating a more rigid plan may require more self-discipline.

Targets. Ideal targets for $\mathrm{HbA}_{1 c}$, blood pressure, cholesterol and weight have been established. While these targets may ultimately apply, it is important to help patients set interim targets that are designed to bring them closer to the ideal. For example, if the $\mathrm{HbA}_{1 \mathrm{c}}$ level is $10 \%$, success may be more likely if the patient's goal is to reduce it one percentage point at a time.

Formulate the self-management plan This is the 'what' of selfmanagement. This is where patients need to consider and choose from the many options identified through learning about diabetes and themselves. These include meal planning, exercise, medications, insulin, blood glucose monitoring, stress management, problem-solving and emotional support. The plan also needs to encompass the ability of patients to incorporate these strategies into their lives.

\section{Experiment and evaluate}

This last step of the LIFE process recognises that all of the LIFE steps are fluid and continuous. Much of the plan will be trial and error. This is the implementation phase of the plan. Nurses can help patients create behavioural or action goals to make the plan a reality. There are five steps in this process: ${ }^{5}$

- Define the problem or concern

- Recognise your emotional response to this issue

- Choose a long-term goal to address this issue

- Make a plan to reach the goal by identifying specific behaviours or action steps towards reaching the goal

- Evaluate the outcome.

It is critical for patients to understand the experimental nature of diabetes self-management. Diabetes care is not a perfect science. This should be the third lesson in patient education. Regardless of the outcome, the patient has the opportunity to learn from the experience. When something in the plan works, it should be continued. If a part of the plan is not working, however, it is critical for nurses to help patients understand the reasons so they can make any necessary adjustments. Sometimes the plan does not work because of a decision to ignore it. Some people may refer to this as 'cheating', but in reality it is a choice.

The fourth lesson is to teach patients that diabetes selfmanagement is not easy. It requires knowledge, commitment and a clear understanding of their needs, feelings, priorities and goals. While it is not easy, it is possible. By working collaboratively with their healthcare providers and with the support of 
their loved ones, they can do it. The place to start is to help patients to understand the importance of their role and then to create and believe in a comprehensive plan - or to simply 'think LIFE'.

\section{Conclusion}

It is imperative that we teach patients that they are the managers of their diabetes, how to manage diabetes, that diabetes care is not a perfect science, and that self-management is not easy. The LIFE plan provides a framework to guide patients through this difficult challenge.

\section{Acknowledgements}

Supported in part by grant number NIH5P60 DK20572 and 1 R18 0K062323 from the National Institute of Diabetes and Digestive and Kidney Diseases of the National Institutes of Health.

\section{Conflict of interest statement}

None

\section{References}

1. Piette JD, Glasgow RE. Strategies for improving behavioral and health outcomes among patients with diabetes: self-management education. In: Evidence-based Diabetes Care. Gerstein HC, Haynes RB (eds). Ontario: BC Decker, 2000.

2. Funnell MM, Anderson RM, Arnold MS, et al. Empowerment: an idea whose time has come in diabetes education. Diabetes Educ 1991; 17: $37-41$.

3. Anderson RM. Patient empowerment and the traditional medical model. Diabetes Care 1995; 18: 412-415.

4. Anderson RM, Funnell MM. Patient empowerment: reflections on the challenge of fostering the adoption of a new paradigm. Patient Educ Couns 2005; 57: 153-157.

5. Anderson RM, Funnell MM. The Art of Empowerment: Stories and Strategies for Diabetes Educators, 2nd edn.
Alexandria: American Diabetes Association, 2005.

6. Funnell MM, Anderson RM, Empowerment and self-management education. Clin Diabetes 2004; 22: 123-127.

7. Weiss MA. Empowerment: a patient's perspective. Diabetes Spectr 2006; 19: 116-118.

8. Funnell MM, Anderson RM. Patient empowerment: a look back, a look ahead. Diabetes Educ 2003; 29: 454-464.

9. Funnell MM, Anderson RM, Nwankwo R, et al. A study of certified diabetes educators: influences and barriers. Diabetes Educ 2006; 32: 359-372.

10. Funnell MM, Anderson RM. Patient empowerment. In: Psychology in Diabetes Care, 2nd edn. Snoek FJ, Skinner TC (eds). Chichester: John Wiley and Sons, 2005; 95-108.

11. Anderson RM, Funnell MM, Butler PM, et al. Patient empowerment: results of a randomized controlled trial. Diabetes Care 1995; 18: 943-949.

12. Glasgow RE, Funnell MM, et al. Selfmanagement aspects of the Improving Chronic Illness Care Breakthrough series: design and implementation with diabetes and heart failure teams. Ann Behav Med 2002; 24: 80-87.

13. Norris SL, Lau J, Smith SJ, et al. Self-management education for adults with type 2 diabetes: a metaanalysis on the effect on glycemic control. Diabetes Care 2002; 25: 1159-1171.

14. Anderson RM, Funnell MM, Nowankwo R, et al. Evaluating a problem based empowerment program for African Americans with diabetes: results of a randomized controlled trial. Ethn Dis 2005; 15: 671-678.

15. Arnold MS, Butler PM, Anderson RM, et al. Guidelines for facilitating a patient empowerment program. Diabetes Educ 1995; 21: 308-312.

16. Funnell MM, Nwankwo R, Gillard ML, et al. Implementing an empowerment-based diabetes self-management education program. Diabetes Educ 2005; 31: 53-61.

17. Tang TS, Gillard ML, Funnell MM, et al. Developing a new generation of ongoing diabetes self-management support interventions: a preliminary report. Diabetes Educ 2005; 31: 91-97.

18. Tang TS, Funnell MM, Anderson RM. Group education strategies for diabetes self-management. Diabetes Spectr 2006; 19: 99-105.

19. Deakin T, McShane CE, Cade JE, $e t$ al. Review: group based education in self-management strategies improves outcomes in type 2 diabetes mellitus. Cochrane Database Syst Rev 2005; (2): CD003417.

20. Kulzer B, Hermanns N, Reinecker $\mathrm{H}$, Haak T. Effects of self-management training in type 2 diabetes: a randomized, prospective trial. Diabet Med 2007; 24: 415-423.

21. Deakin TA, Cade JE, Williams R, Greenwood DC. Structured patient education: the Diabetes X-PERT programme makes a difference. Diabet Med 2006; 23: 944-954.

22. Von Korff M, Gruman J, Schaefer J, et al. Collaborative management of chronic illness. Ann Intern Med 1997; 27: 1097-1102.

23. Polonsky WH, Earles J, Smith S, et al. Integrating medical management with diabetes self-management training: a randomized control trial of the Diabetes Outpatient Intensive Treatment Program. Diabetes Care 2003; 26: 3048-3053.

24. Skovlund SE, Peyrot M, on behalf of the DAWN International Advisory Panel. The Diabetes Attitudes, Wishes and Needs program: a new approach to improving outcomes of diabetes care. Diabetes Spectr 2005; 18: 136-142.

25. Green AJ, Bazata DD, Fox KM, Grandy S for the SHIELD Study Group. Health-related behaviours of people with diabetes and those with cardiometabolic risk factors: results from SHIELD. Intl J Clin Pract 2007; 61: 1791-1797.

26. Weiss MA, Funnell MM. The Little Diabetes Book You Need to Read. Philadelphia: Running Press, 2007.

27. Weiss MA, Funnell MM. Your diabetes management plan: why it pays to have one. Diabetes Self Manag 2006; 23: 46-51. 